\title{
Building Heating Process: Numerical Analysis of the Impact of Moisture and the Type of Concrete
}

\author{
Christophe Songong Tsakeu ${ }^{1}$, Elie SIMO ${ }^{2, *}$, Josue Ivan Charles Zambe ${ }^{1}$, \\ Steve Franklin William Tabekoueng ${ }^{1}$, Stephane Nguifo Sob ${ }^{2}$ \\ ${ }^{1}$ Department of Physics, Laboratoire de Sciences des Matériaux, Faculty of Science, University of Yaounde I, Cameroon
${ }^{2}$ Department of Physics, Laboratory of Energy and Environment, Faculty of Science, University of Yaounde I, Cameroon
}

Received June 2, 2021; Revised July 19, 2021; Accepted August 22, 2021

\section{Cite This Paper in the following Citation Styles}

(a): [1] Christophe Songong Tsakeu, Elie Simo, Josue Ivan Charles Zambe, Steve Franklin William Tabekoueng, Stephane Nguifo Sob, "Building Heating Process: Numerical Analysis of the Impact of Moisture and the Type of Concrete," Civil Engineering and Architecture, Vol. 9, No. 6, pp. 1785-1797, 2021. DOI: 10.13189/cea.2021.090612.

(b): Christophe Songong Tsakeu, Elie Simo, Josue Ivan Charles Zambe, Steve Franklin William Tabekoueng, Stephane Nguifo Sob (2021). Building Heating Process: Numerical Analysis of the Impact of Moisture and the Type of Concrete. Civil Engineering and Architecture, 9(6), 1785-1797. DOI: 10.13189/cea.2021.090612.

Copyright $\subseteq 2021$ by authors, all rights reserved. Authors agree that this article remains permanently open access under the terms of the Creative Commons Attribution License 4.0 International License

\begin{abstract}
We numerically performed the influence of moisture, external temperature and the type of concrete on the energy provided for buildings heating. The coefficient of diffusion is not taken as a constant. We developed a technique based on DOPRI5 fourth-and-fifth-order Runge-Kutta variable step integrator. Investigations were conducted in the range of $-5: 20^{\circ} \mathrm{C}$, which cover the majority of thermal conditions in which people live. As a result, energy consumption increased both with the increasing level of moisture content and with the decreasing level of the external temperature. For instance, in the case or normal concrete, when the outside temperature was $T_{1}=15^{\circ} \mathrm{C}$, the power of building heating was $30 \mathrm{~W} / \mathrm{m}^{2}$ and when it was $T_{1}=-5^{\circ} \mathrm{C}$, the power of building heating became $175 \mathrm{~W} / \mathrm{m}^{2}$. We have found that the presence of moisture induces additional energy expenditures. Two different types of concrete were involved in this study, namely normal concrete and pumice concrete. For an outdoor temperature of $-5^{\circ} \mathrm{C}$, the required heating power was $175 \mathrm{~W} / \mathrm{m}^{2}$ in the case of a normal concrete wall. On the other hand, we needed only about $87.7 \mathrm{~W} / \mathrm{m}^{2}$ when the wall was made of pumice concrete, showing that energy expenditure for pumice concrete was half that of normal concrete.
\end{abstract}

Keywords Buildings Made in Concrete, Heating Process, Moisture Impact, Diffusion Process, Runge-Kutta 4-5 Orders

\section{Introduction}

In this paper, we address the problem of the inefficient usage of energy. We restrict our attention to the problematic of buildings heating. A large share of the worldwide energy consumption is attributed to the heating of buildings during winter period. Building heating refers to the energy needed for warming buildings, whether residential or in the service sector, such as schools, hospitals, enterprises and office buildings. A number of households experience great difficulty to estimate the costs of heating due to the climate changes and to the poor condition of the houses. It is essential to reduce energy consumption in buildings in order to meet global energy and environmental challenges.

We should not neglect any option that could contribute to the aspired saving of resources. The critical tool to ease pressure on energy consumption is to ensure energy efficiency [1], because we believe that energy efficiency is the key to sustainable development. It is urgent that an effective optimization of energy be used for warming.

According to the European Union report [2], the heating sector accounts for about $35 \%$ of the EU's annual energy consumption. Something must be done to downgrade the quantity of energy involved in this sector. This is the biggest energy challenges facing humanity. One should develop strategies leading to the optimum heating of buildings. By doing so, emissions of dangerous pollutants will be reduced. This will be a concrete action 
contributing to the protection of our environment. It is a fact that energy and environment are two related concepts. So, a strategy that does not aim at reducing the cost of energy consumption must be neglected. This paper deals with issues related to the energy provided for the heating of buildings, more precisely during winter period. In fact, no life can be imagined in a building, during this period, without energy. It is important to address this problem because the main function of a house is to provide occupants with a comfortable, safe, and attractive living and working environment. Such initiative is designed to improve the life of the residents.

One of the crucial demands of a central heating system in building is to accurately maintain the desired room temperature. By doing so, one permanently ensures the thermal comfort of its occupants. In this sense, the heating power has to be adequately adapted in the course of time. Hence, a modern control system should be able to adjust the heating power automatically, according to the weather conditions. Our attention shall be particularly focused on the impact of the fluctuation of the external temperature, the type of concrete and the rate of moisture content in the building heating process.

Most of the building materials are presented as hygroscopic porous media. In this sense, they show a greater affinity to water [3-6]. The primary goal in a building structure should be to keep water out of the building components or at least significantly lower their content. However, the continuous presence of excessive moisture in concrete is the most problematic. In fact, thermal conductivity coefficient increases with increasing moisture content. As such, there is always a considerable diffusion of heat through the walls leading to more loss of energy during the heating process. It is also important that building walls be maintained in a perfect dry status to ensure concrete strength and safety [7]. This work addresses the problem of the effects of moisture content and external temperature on the amount of energy necessary for the heating of buildings. In fact, temperature and moisture content are important parameters affecting thermal properties of concrete [8].

The paper is organized as follows: The next section is devoted to the materials and methods. Section three stands for implementation of the DOPRI5 numerical code. In this section, the computational results are followed by discussions and commentaries.

\section{Materials and Methods}

\section{Presentation of the model}

In the context of building physics, the transport of liquid in the construction materials is considered to be based on a diffusion phenomenon. On the assumption that there is no generation or absorption of the moisture by the system, the nonlinear equation of the moisture transport in such a porous media is given as

$$
\frac{\partial \omega}{\partial \tau}=\nabla \cdot[\mathrm{D} \omega \nabla \omega]
$$

Where, $\omega$ stands for the moisture content, $D_{\omega}$ is the moisture diffusivity and $t$ is the duration of the process. See, for instance, references [9-10]. The coefficient of diffusivity is a key parameter which measures the rate of penetration of moisture in the wall. Once the imbibing surface of the wall is fully wet, a suction capillary process takes place. In this contribution, the coefficient of diffusivity is not considered as a constant entity according to the following equation [11]:

$$
D_{\omega}=3.8\left(\frac{\mathrm{A}}{\omega f}\right)^{2} 1000^{\frac{\omega}{\omega f}-1}
$$

Here, the parameter A stands for the sorption coefficient, and $\omega_{f}$ represents the moisture content at capillary saturation. In the conditions of daily use, concrete cannot be considered as being in a moisture-free condition. The physical characteristics of the concrete are altered by the sustained presence of moisture. This is precisely the case with the thermal conductivity coefficient, as we mentioned earlier, which needs to be corrected in such circumstances. Cammerer and its colleagues [12] have demonstrated that the thermal conductivity coefficient is naturally moisture-dependent. The expression of which being given as:

$$
\lambda_{\omega}=\lambda_{0}\left[1+\frac{b \omega}{\rho_{S}}\right]
$$

$\lambda_{\omega}$ is the thermal conductivity of wet material; $\lambda_{0}$ refers to the thermal conductivity of dry building material and $\rho_{S}$ the bulk density of dry building material. The parameter b represents the thermal conductivity supplement. The latter indicates by how many percent the coefficient of the heat conductivity increases percentage mass of moisture [11]. The thermal conductivity reflects the capacity of the concrete to transferring heat. Extremely low values of this coefficient are related to good building material insulations. In this sense, we experience optimal energy savings as the loss of energy is negligible. The heat conduction in the material is described by the Fourier's law and is given by:

$$
\varphi=-\lambda_{\omega} \nabla T
$$

In this notation, $\varphi$ stands for the local heat flux density and T temperature of the concrete. Now, we can derive the power provided for the heating of the building from this relation (4):

$$
\boldsymbol{\Phi}=\frac{\lambda_{\omega} S\left(T_{i}-T_{e}\right)}{L}
$$


Here, $\mathbf{\Phi}$ represents the power supplied for the heating, $S$ is the section of the wall, $L$ is the wall thickness; $T_{i}$ is the temperature at the inner face of the wall; $T_{e x}$ is the temperature at the outer face of the wall. So, the temperature of the building wall at position $\mathrm{x}$ on a weathered surface is given by:

$$
T_{x}=T_{e x}+\frac{x \Phi}{\lambda_{\omega}}
$$

The key point that should be emphasized in this work is that the thermal conductivity of the concrete is moisture-dependent. So, what shall be the impact of moisture in the heating process of the building? We address this question in terms of the amount of energy expended for the heating.

Each computed value of the moisture content, $\omega$, is associated with the thermal conductivity expressed by the formula (3) above. A peak of energy consumption is observed in households and in other buildings during the winter period for heating requirements.

Numerical resolution of the diffusion equation by the method of Runge-kutta of the fourth-and-fifth-orders using the dopri5 code as the integrator: energy computation.

As can be seen, the analytical solvability of the processing of this model is questionable due to the fact that the nonlinear diffusion equation (1) governing the system does not have an obvious analytical solution, so we opted for a numerical computation. These equations could be solved computationally using numerical analysis methods. It should be recalled that only a quite stable numerical analysis could lead to physically acceptable solutions. A numerical method is said to be stable if numerical errors, for example those errors generated by roundoff, are not amplified, and the approximate solution remains bounded. This requirement applies to time-stepping schemes and iterative solvers alike. It is worth noticing that the notion of stability highlights the relationship between the exact solution of the discrete problem and the actually computed solution that includes any roundoff and iteration errors.

Nowadays, all the mathematical tools necessary for the study of stability are available in the case of linear problems with constant coefficients. The most popular technique is, unquestionably, the well-known Von Neumann method. See, for instance, references [13-15]. On the other hand, nonlinear problems are more difficult to analyze which may require a stronger form of stability. So, it is important to solve this problem using an appropriate technique. In this sense, the Runge Kutta method using DOPRI5 as the integrator [10, 15, 16-21], which is introduced accurately to describe the nonlinear diffusion of moisture in porous building materials such as concrete. The basis of the method is to discretize the spatial part of the operator and keep the temporal part as such. This approach allows for an increase in the precision of the approximation in time and space independently and easily. We choose the finite volume approximation for the space discretization where the operator is integrated over the reference volumes. As the solver for the differential equations, we use the Runge-Kutta method of orders 4-5 introduced by Dormand and Prince [22] which was implemented as the Fortran code by Hairer and Norsett [15]. This solver enables us to control the local error by varying the time step. With the necessary data input, the model calculates the resulting moisture content and the power provided for heating.

Table (1) represents the input data used for the computational process according to references [11, 12]. Our numerical investigations focused on two different types of concrete as building material; namely, normal concrete and pumice concrete.

Table 1. Input data related to different types of concrete

\begin{tabular}{lccccc}
\hline Type of concrete & $\begin{array}{c}\text { bulk density } \\
{\left[\mathrm{kg} / \mathrm{m}^{3}\right]}\end{array}$ & thermal conductivity & $\begin{array}{c}\text { moisture supplement } \\
{[\%]}\end{array}$ & $\begin{array}{c}\text { free water saturation } \\
{\left[\mathrm{kg} / \mathrm{m}^{3}\right]}\end{array}$ & $\begin{array}{c}\text { water absorption } \\
\text { coefficient } \\
{\left[\mathrm{kg} /\left(\mathrm{m}^{2} s^{1 / 2}\right)\right]}\end{array}$ \\
\hline Normal concrete & 2300 & 1.40 & 8 & 128 & 0.228 \\
Pumice concrete & 1550 & 0.70 & 4 & 277 & 0.166 \\
\hline
\end{tabular}

Table 2. Power provided for heating. Here, the walls of the building are made of normal concrete. The moisture content is set at $\omega=100 \mathrm{Kg} / \mathrm{m}^{3}$

\begin{tabular}{|c|c|c|c|c|c|c|c|c|}
\hline $\begin{array}{c}\text { External } \\
\text { Temperature }\left[{ }^{\circ} \mathrm{C}\right]\end{array}$ & 15 & 13 & 10 & 6 & 4 & 0 & -4 & -5 \\
\hline $\begin{array}{c}\text { Power of building } \\
\text { heating }\left[\mathrm{W} / \mathrm{m}^{2}\right]\end{array}$ & 30 & 49 & 70 & 98 & 112 & 149 & 168 & 175 \\
\hline
\end{tabular}

Table 3. Power provided for heating. Here, the walls of the building are made of pumice concrete. The moisture content is set at $\omega=100 \mathrm{Kg} / \mathrm{m}^{3}$

\begin{tabular}{|c|c|c|c|c|c|c|c|c|}
\hline $\begin{array}{c}\text { External } \\
\text { Temperature }\left[{ }^{\circ} \mathrm{C}\right]\end{array}$ & 15 & 13 & 10 & 6 & 4 & 0 & -4 & -5 \\
\hline $\begin{array}{c}\text { Power of building } \\
\text { heating }\left[{\left.\mathrm{W} / \mathrm{m}^{2}\right]}^{2}\right.\end{array}$ & 18 & 24 & 35 & 48 & 55 & 70 & 83 & 87 \\
\hline
\end{tabular}




\section{Results and Discussion}

In this paper, we numerically investigate the influence of the moisture content in walls made of concrete. Our survey takes into account the weather outside the building.

The first thing that we can emphasize is that: the type of the materials used for building construction plays a crucial role. If we examine critically results exhibited in tables 2 and 3, we realize that the amount of energy required for heating when the walls are made of pumice concrete is almost $50 \%$ less than that is involved in the heating process when the building walls are constructed using normal concrete. Furthermore, there is a significant difference in price between the two materials. The pumice concrete becomes more costly than the normal concrete. So, a choice should be made for buildings. We can decide to spend a lot of money during the construction by putting enough money in the quality of the material used. This money shall be recovered during the periods of heating. By doing so, this shall be, not only an opportunity to save money, but also an opportunity to contribute to the protection of the environment. So, the use of concretes of higher quality ensures thermal comfort and energy efficiency. Furthermore, the value of the external temperature influences seriously the total amount of energy required for heating. Each table above indicates that, the heating power increases as the external temperature decreases.

In order to deal with this heating problem, the Energy
Assistance Program provides some county residents with a one-time annual payment to make heating energy bills more affordable. Hence, this funding pays a portion of energy costs. From our point of view, we would suggest that, instead of planning for such annual assistance, this program would rather elaborate their assistance during the stage of construction to improve the technical quality of the building, assistance in view of assuring the quality of the materials used and the technical aspect of their building. By so doing, they could definitely lower the cost of heating energy. The main objective should be to help them save enough energy and keep the charges relating to the energy consumption at a manageable level.

Under an efficient global case concerning the technical aspect of the construction of buildings, as well as the type of materials utilized, energy consumption for heating could be significantly reduced. It is important to focus mostly on the solution to long durations instead of coming toward the population, from time to time (more specifically toward the most vulnerable strata) to help them in supporting the loads related to the heating energy.

In the case where the wall of the building is made of normal concrete, one can notice that temperature inside the wall building increases with moisture content. The growth is moderate for small values of moisture content, and very pronounced for large values of moisture content. The average temperature of the wall increases with the time period. This is visible in Figure 1 where each individual curve corresponds to a given time period.

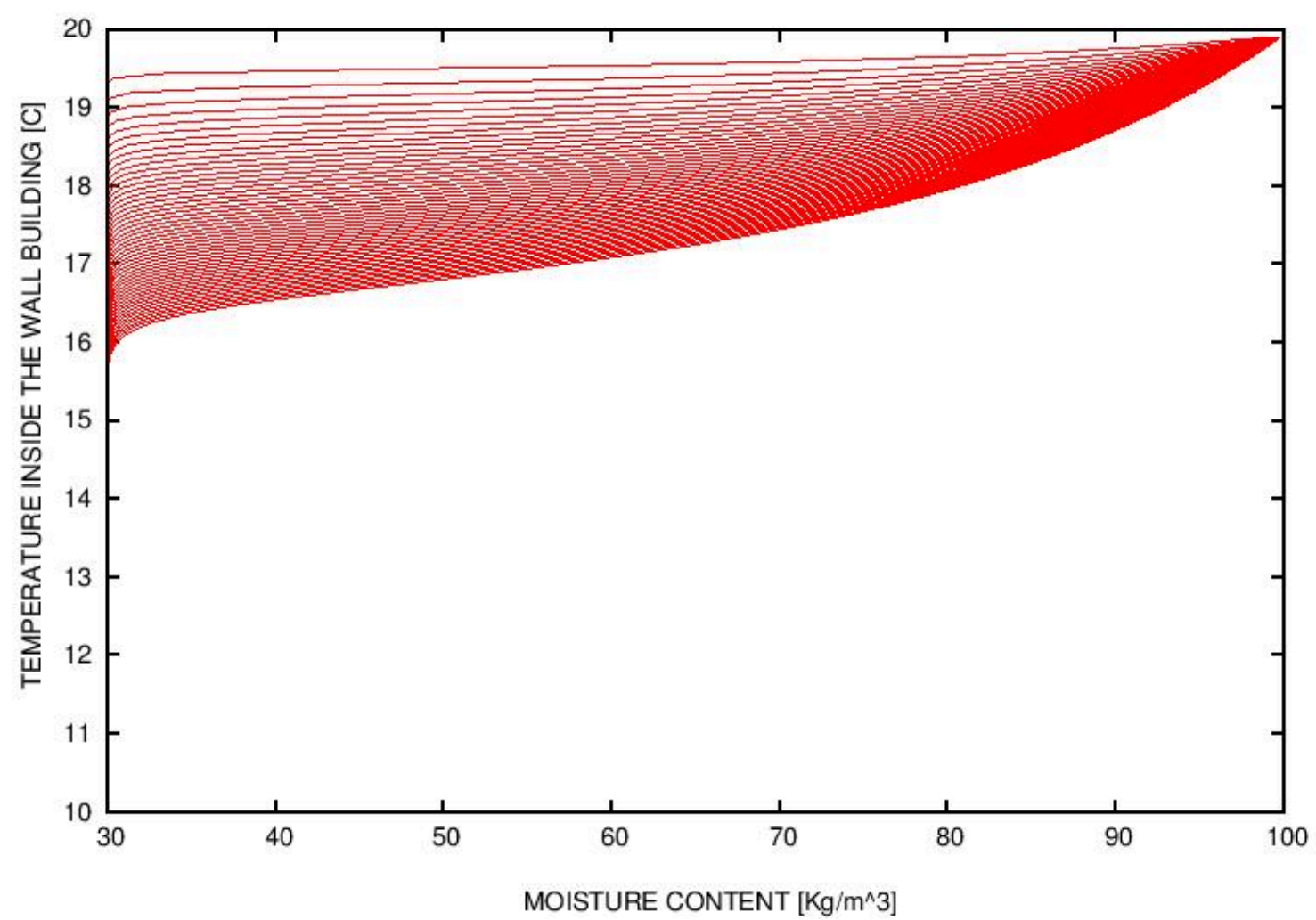

Figure 1. Temperature in the wall made of normal concrete as a function of the moisture content. The initial moisture content on the weathered surface is $\omega_{0}=100 \mathrm{Kg} / \mathrm{m}^{3}$. The external temperature is $10^{\circ} \mathrm{C}$. Curves are plotted at successive time periods. 


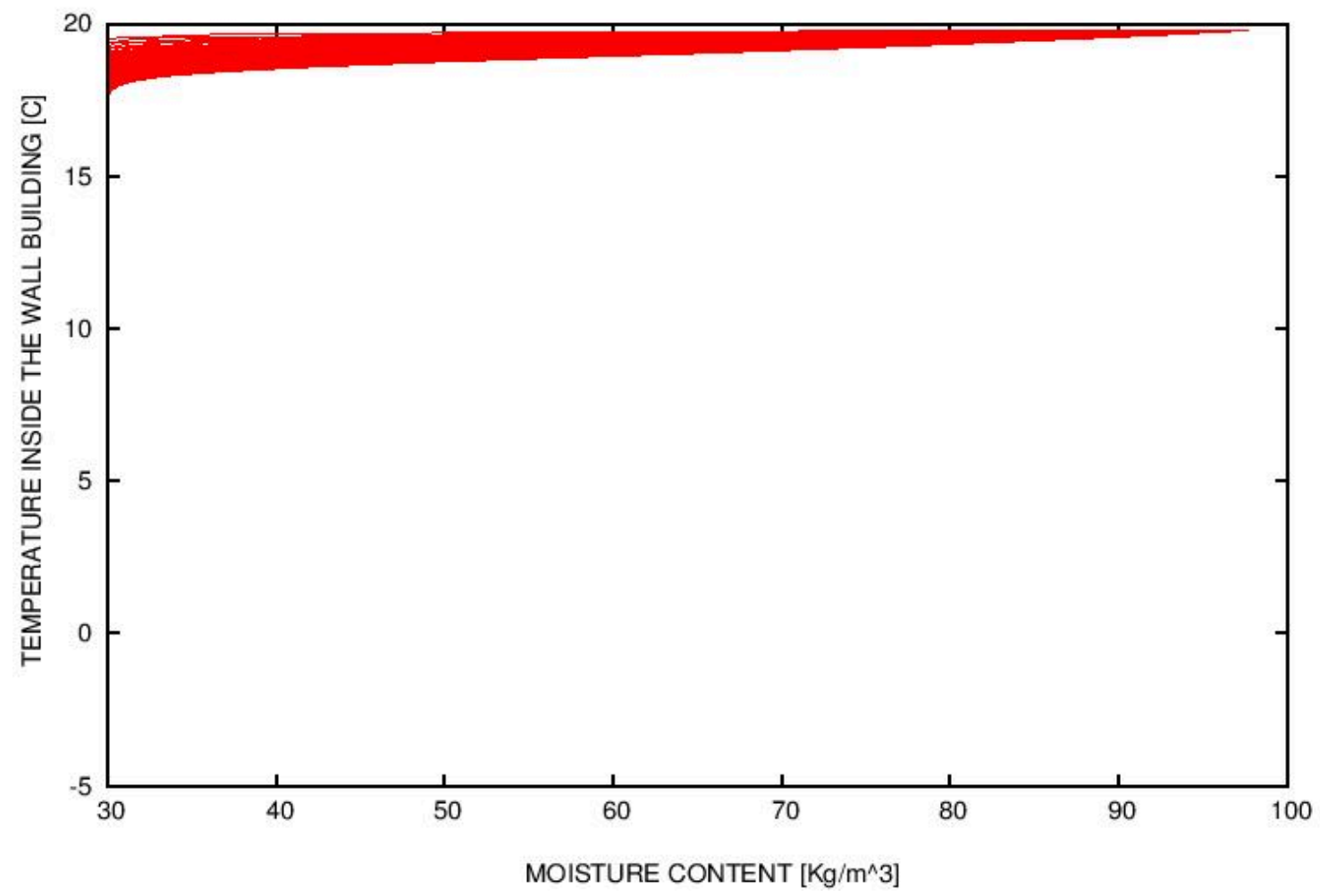

Figure 2. Temperature in the wall made of pumice concrete as a function of moisture content. The initial moisture content on the weathered surface is $\omega_{0}=100 \mathrm{Kg} / \mathrm{m}^{3}$. The external temperature is $-5^{\circ} \mathrm{C}$.

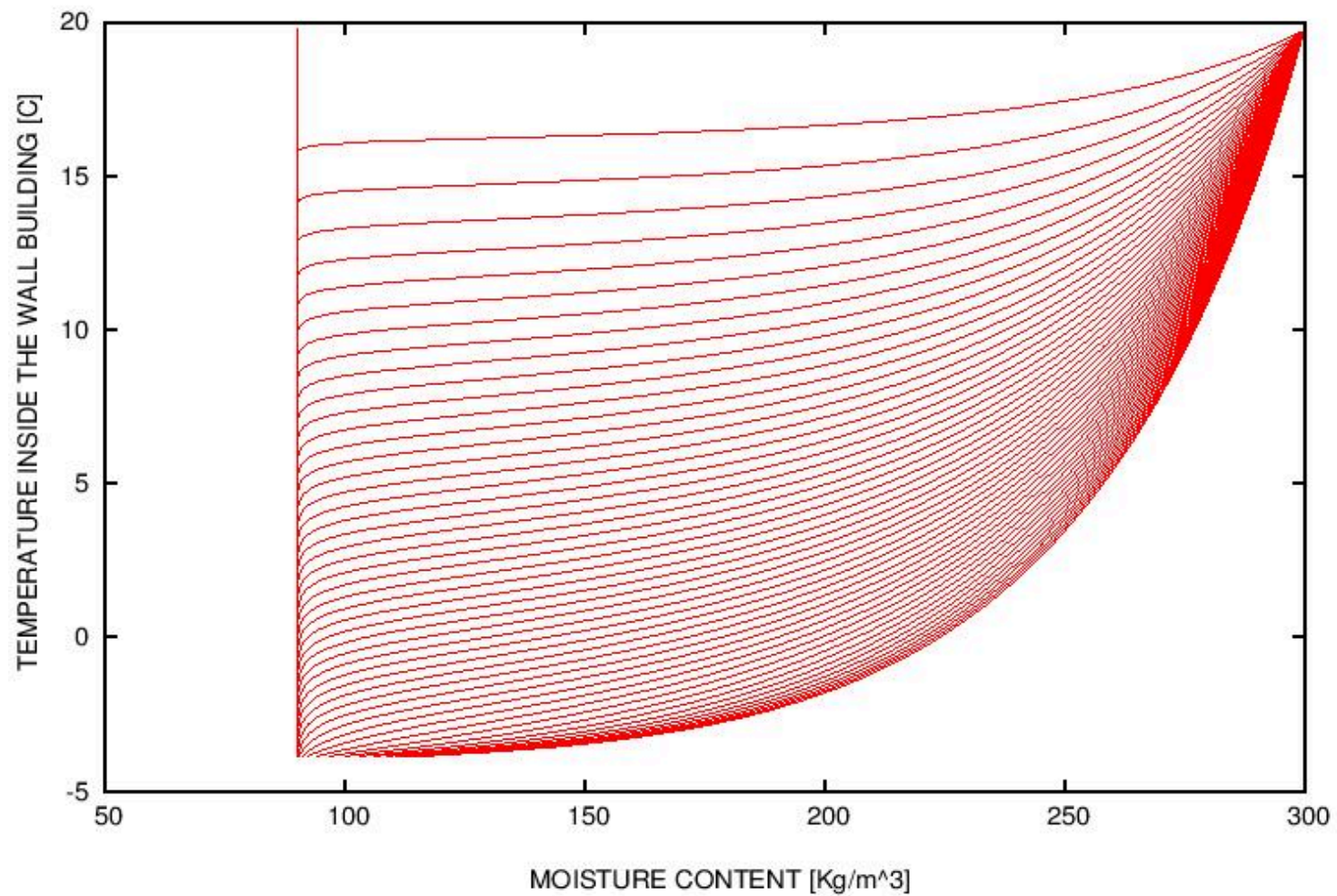

Figure 3. Temperature in the wall made of pumice concrete as a function of moisture content. The initial moisture content on the weathered surface is $\omega_{0}=300 \mathrm{Kg} / \mathrm{m}^{3}$. The external temperature is $-5^{\circ} \mathrm{C}$.

Considering the pumice concrete in the building process, it appears that the temperatures of the wall are mostly concentrated near the maximum values reachable, that is $20^{\circ} \mathrm{C}$, when the initial moisture content takes a small value, $\omega_{0}=100 \mathrm{Kg} / \mathrm{m}^{3}$. This statement can be verified in the Fig. 2. The situation is different for a 
somewhat higher value of $\omega_{0}=300 \mathrm{Kg} / \mathrm{m}^{3}$ : The temperatures of the wall, for different time periods, are extended from the value $-5^{\circ} \mathrm{C}$ to the maximum value $20^{\circ} \mathrm{C}$ (see figure 3). Thus, low temperatures are allowed in this case. All curves converge naturally toward the value $20^{\circ} \mathrm{C}$, the temperature imposed inside the building by the heating mechanism.

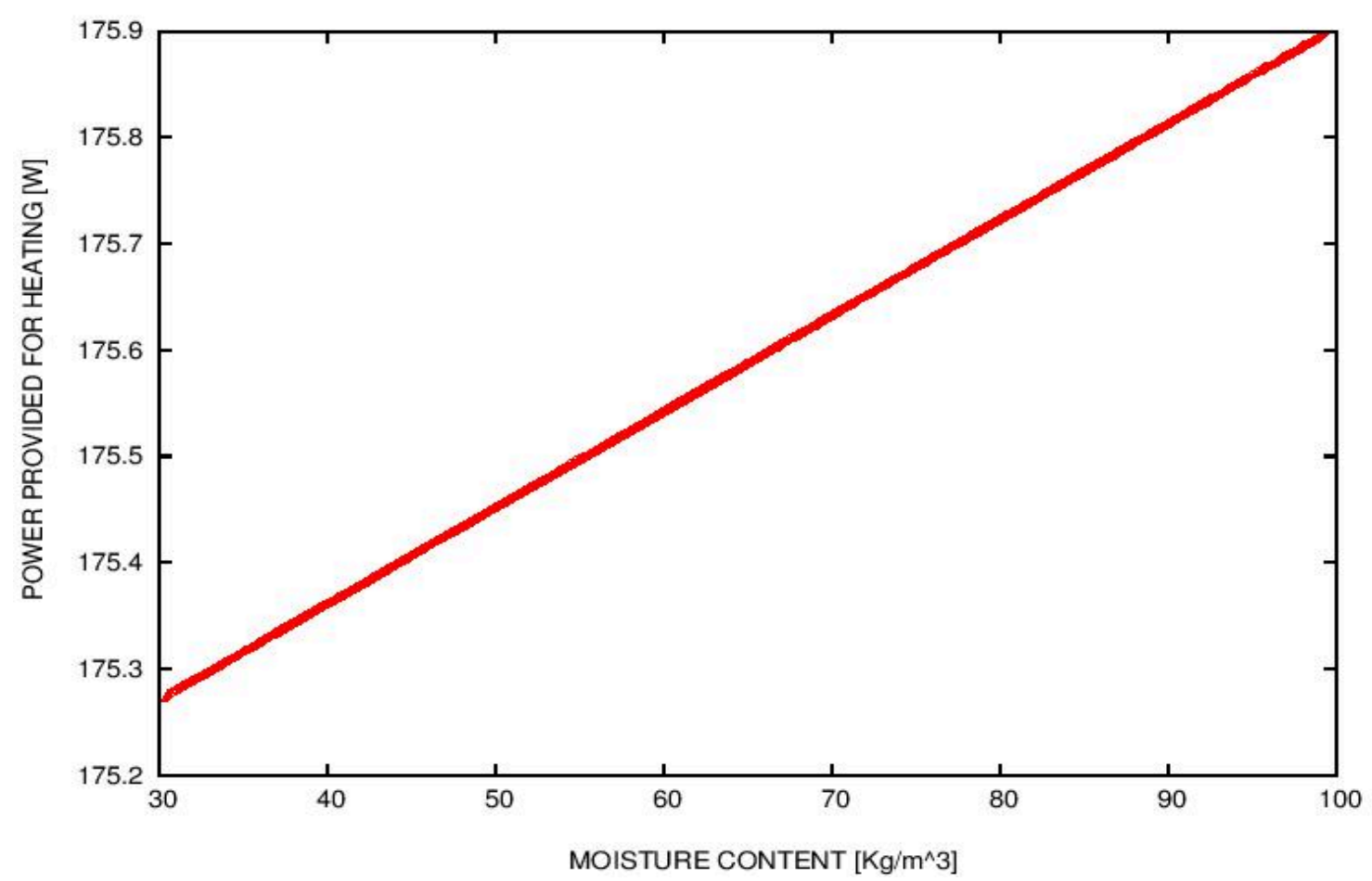

Figure 4. Power provided for heating in terms of moisture content. Here, the wall is made normal concrete. The initial moisture content on the weathered surface is $\omega_{0}=100 \mathrm{Kg} / \mathrm{m}^{3}$. The external temperature is $-5^{\circ} \mathrm{C}$.

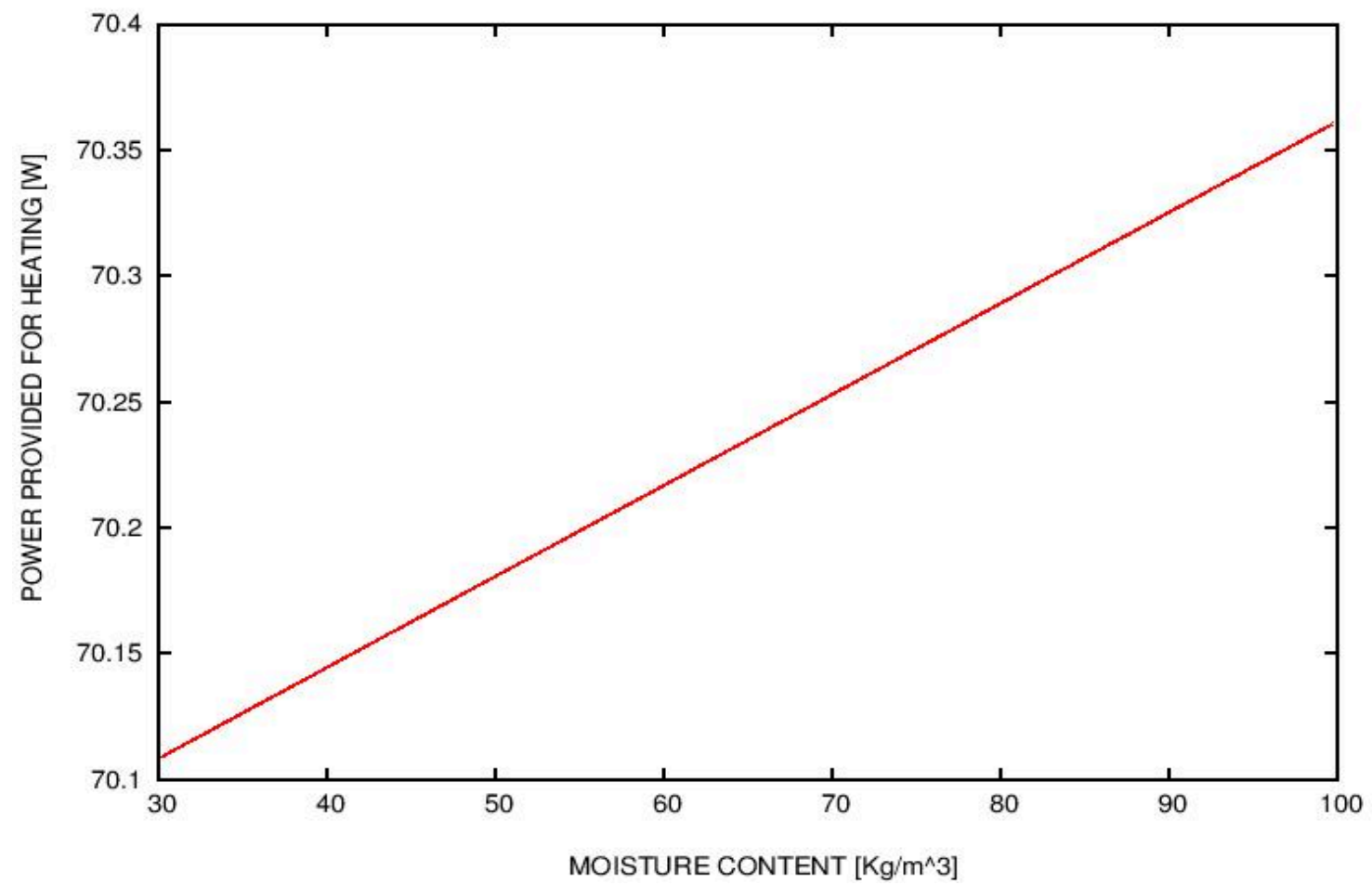

Figure 5. Power provided for heating in terms of moisture content. Here, the wall is made of normal concrete. The initial moisture content on the weathered surface is $\omega_{0}=100 \mathrm{Kg} / \mathrm{m}^{3}$. The external temperature is $10^{\circ} \mathrm{C}$. 


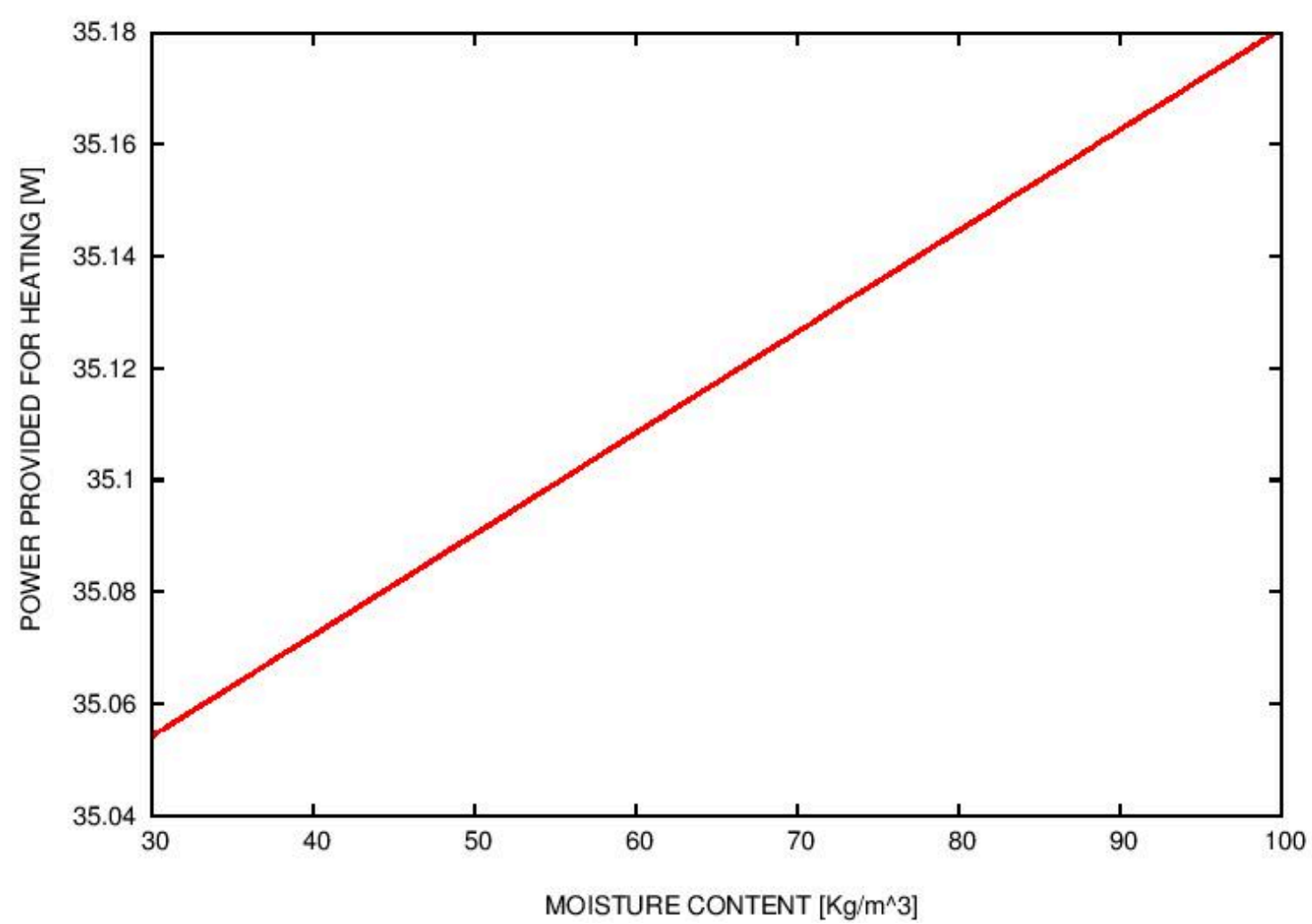

Figure 6. Power provided for heating in terms of the moisture content. Here, the wall is made by normal concrete. The initial moisture content on the weathered surface is $\omega_{0}=100 \mathrm{Kg} / \mathrm{m}^{3}$. The external temperature is $15^{\circ} \mathrm{C}$.

Figures 4,5 and 6 show the impact of moisture content in the power provided for heating. Here, the buildings are made of normal concrete. The same calculations are made for buildings made of pumice concrete. The reader can refer to figures 7 and 8 . It is natural to note that the external temperature plays a crucial role in the amount of energy involved in the heating process. In fact, the lower the moisture content in the wall, the higher the energy demand necessary to maintain the inner temperature at the value $20^{\circ} \mathrm{C}$, a temperature that can ensure a thermal comfort. As one can see from these figures, the change is very significant, in terms of the ambient temperature and the type of concrete. So, when the temperature of the locality is around $15^{\circ} \mathrm{C}$, just $35 \mathrm{~W} / \mathrm{m}^{2}$ shall be involved in the heating process. This amount of power shall be doubled if the external temperature decreases to the value $10^{\circ} \mathrm{C}$. By contrast, in localities where temperatures in winter period reach very low values, $-5^{\circ} \mathrm{C}$ for example, energy consumption becomes really important. In this case, the calculations show that $175 \mathrm{~W} / \mathrm{m}^{2}$ is required for a normal heating of the building. The same computations are made with the pumice concrete. The results obtained are very different: An external temperature of $15^{\circ} \mathrm{C}$ corresponds to $17 \mathrm{~W} / \mathrm{m}^{2}$ of power provided for the heating. However, $87 \mathrm{~W} / \mathrm{m}^{2}$ shall be involved in heating in a locality where the temperature is around $-5^{\circ} \mathrm{C}$. The heating energy doubles practically when we use the pumice concrete instead of normal concrete. These results are displayed in Figs. 10 and 11. 


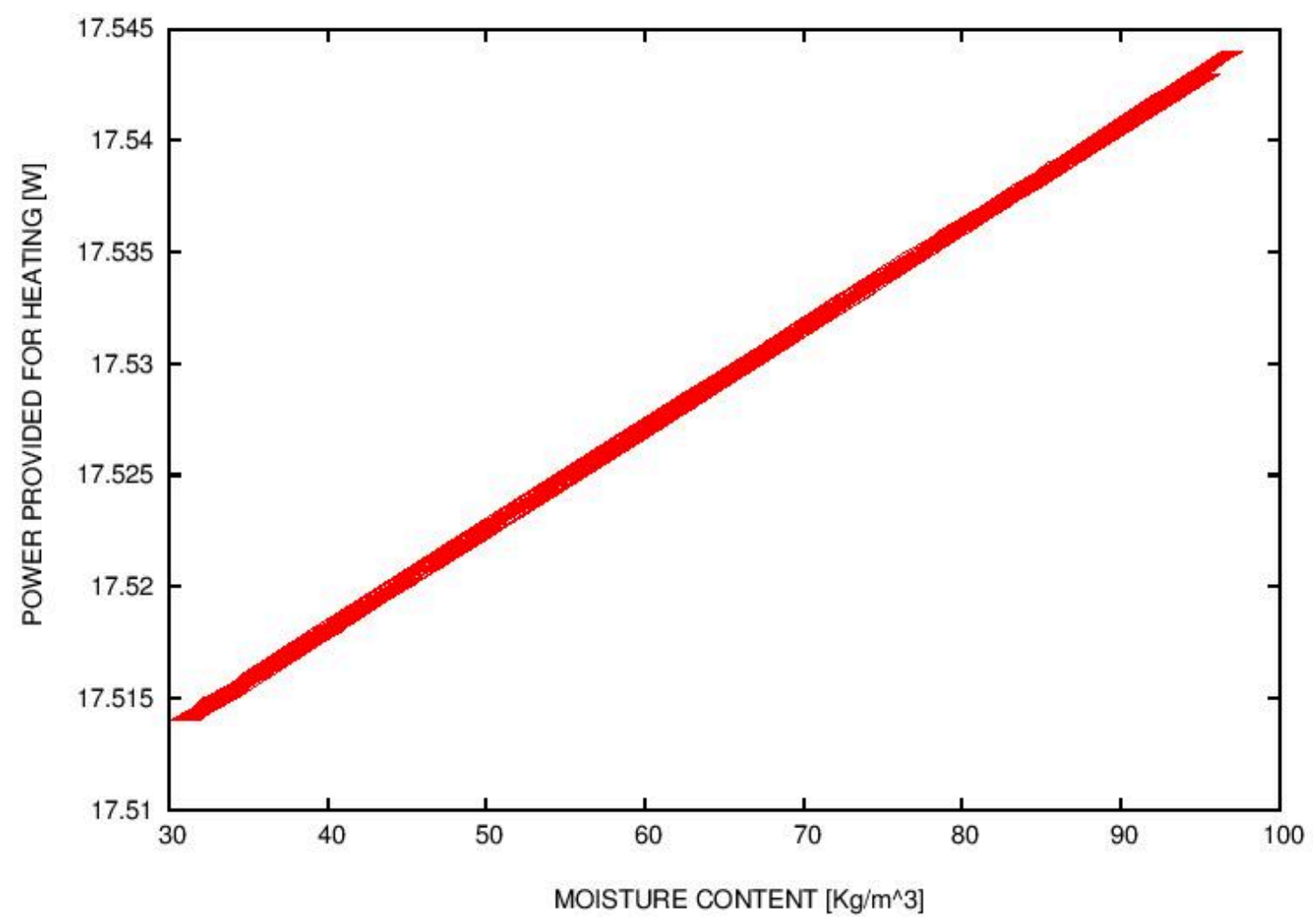

Figure 7. Power provided for heating in terms of moisture content. Here, the wall is made of pumice concrete. The initial moisture content on the weathered surface is $\omega_{0}=100 \mathrm{Kg} / \mathrm{m}^{3}$. The external temperature is $-5^{\circ} \mathrm{C}$.

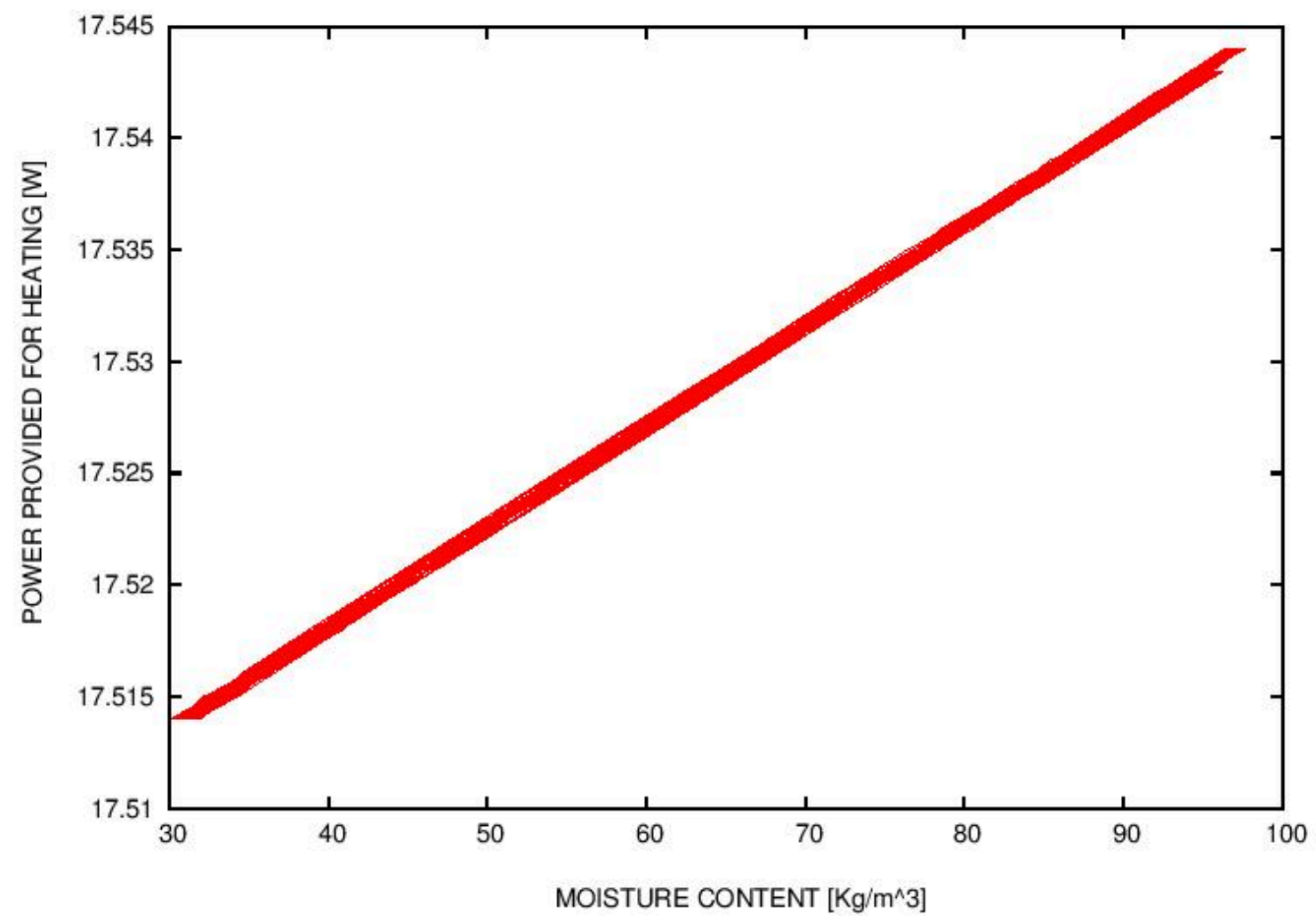

Figure 8. Power provided for heating in terms of moisture content. Here, the wall is made of pumice concrete. The initial moisture content on the weathered surface is $\omega_{0}=100 \mathrm{Kg} / \mathrm{m}^{3}$. The external temperature is $15^{\circ} \mathrm{C}$. 


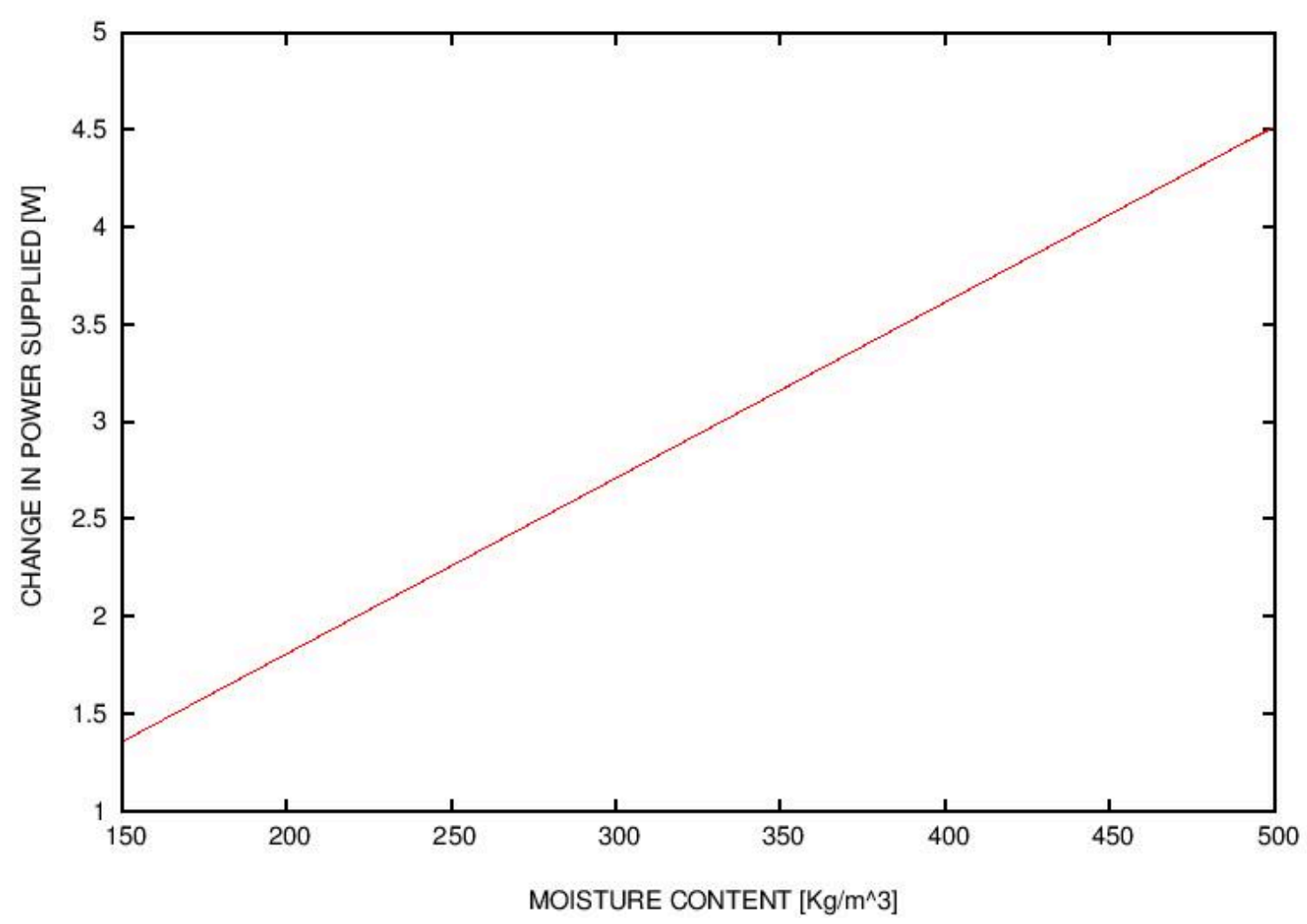

Figure 9. Change in power supplied in terms of moisture content. Here, the wall is made of normal concrete. The initial moisture content on the weathered surface is $\omega_{0}=500 \mathrm{Kg} / \mathrm{m}^{3}$. The external temperature is $-5^{\circ} \mathrm{C}$.

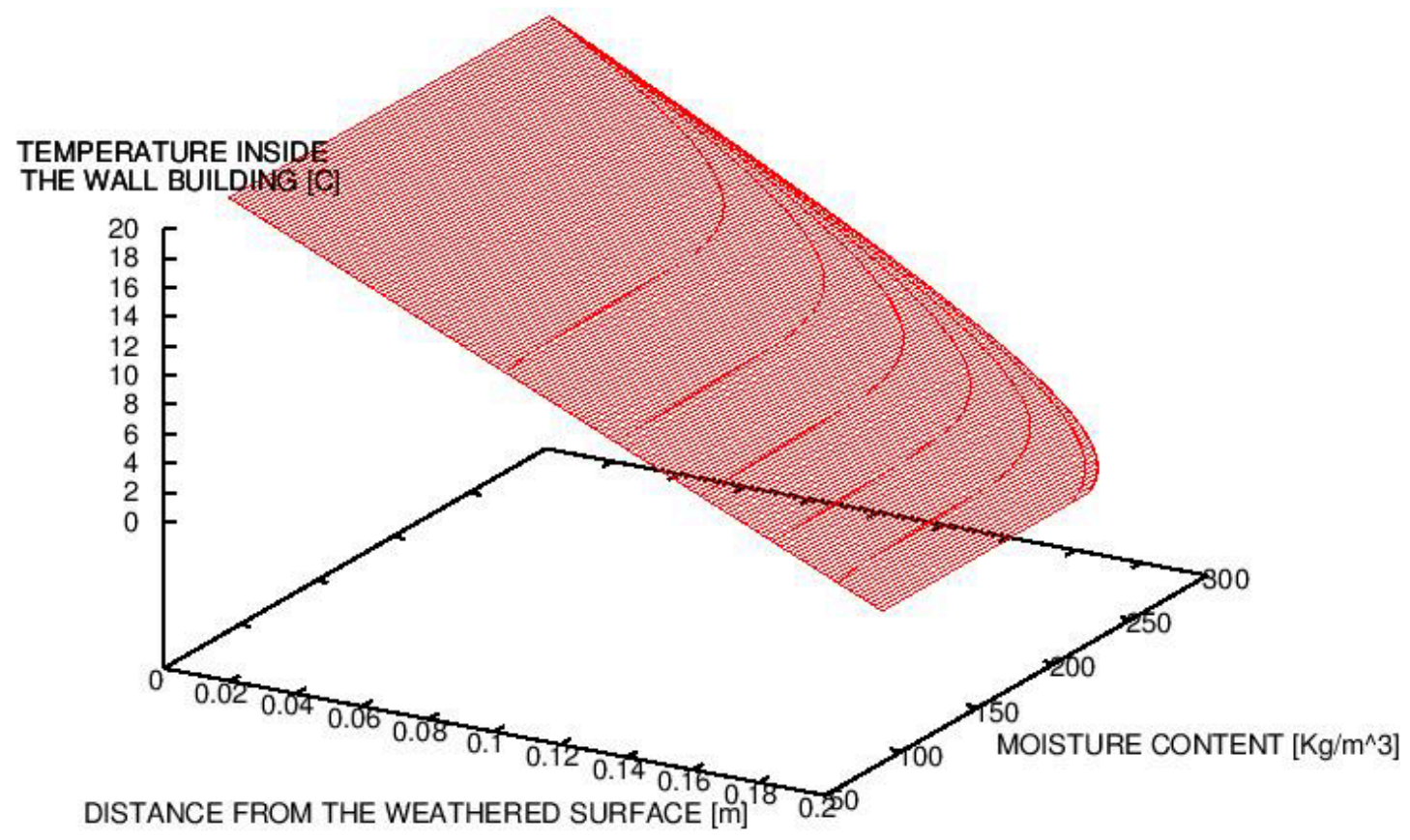

Figure 10. Spatial profile of the temperature of the wall of the building as a function of moisture content. Here, the wall is made of normal concrete. The initial moisture content on the weathered surface is $\omega_{0}=300 \mathrm{Kg} / \mathrm{m}^{3}$. The external temperature is $0^{\circ} \mathrm{C}$

Fig. 9 tells us that change in power supplied in terms of moisture content might be very significant in certain circumstances. Thus, in the case where the temperature of the locality is around $-5^{\circ} \mathrm{C}$, for an initial moisture content of about $\omega_{0}=500 \mathrm{Kg} / \mathrm{m}^{3}$, the change induced in the power supplied, due to the presence of the moisture, can reach the amount of $4,5 \mathrm{~W} / \mathrm{m}^{2}$.

From Figs. 10 and 11, it is shown that the temperature 
inside the wall of the building decreases gradually as one approaches the external surface of the wall. It should be noticed that the temperature drops drastically to zero when one approaches the external surface of the wall. But this decay is slightly more pronounced in the case of a wall made of pumice concrete. And this, compared to the one made of normal concrete. This situation was expected because the thermal conductivity of normal concrete is higher than that of pumice concrete.

Let's perform calculations on a specific case. This example of calculations shall enable us to have a clear idea on the way moisture and outdoor temperature make a real impact on the total amount of the energy involved in the heating process. We consider a medium building of $10 \mathrm{~m} \mathrm{X} 7 \mathrm{~m}$ and $2,5 \mathrm{~m}$ high. Fig. 9 tells us that the extra heating energy that emerges due to the presence of moisture, at a given outdoor temperature, is around $4,5 \mathrm{~W} / \mathrm{m}^{2}$. At first view, it seems that people do not realize the real magnitude of such phenomenon. Now, if one extends this amount to just a small city of about 100000 buildings having approximately the afore mentioned sizes. One can easily reach additional energy expenses of about $38,25 G W$. It is clear that this amount of energy cannot be neglected at this scale. So, the crucial problem of moisture effect in the process of buildings heating cannot be avoided or put aside. It should be addressed with a maximum of seriousness and attention.

The main objective, within the framework of this work, is to make people understand, through calculations that they must opt for large investments on energy saving materials at the time of construction. This will allow them to benefit from high quality buildings offering good thermal comfort. Thus, later on, they will save a lot of money during the heating process.

In this document, we do not draw special attention to the well-known high humidity areas that are present in every dwelling house, such as kitchens, shower compartments, dressing rooms. In general, all well-trained designers know that special treatment is required in all those regions that are permanently wet. This effectively contributes to lowering heating energy expenditure.

Here, we are more interested in what happens during the summer period when the exterior walls are constantly wet and exposed to intense humidity. During this period, external walls are regularly watered by driving rains. It is during this period that the problem of heating arises acutely. Our development is essentially based on the exterior envelope of the house.

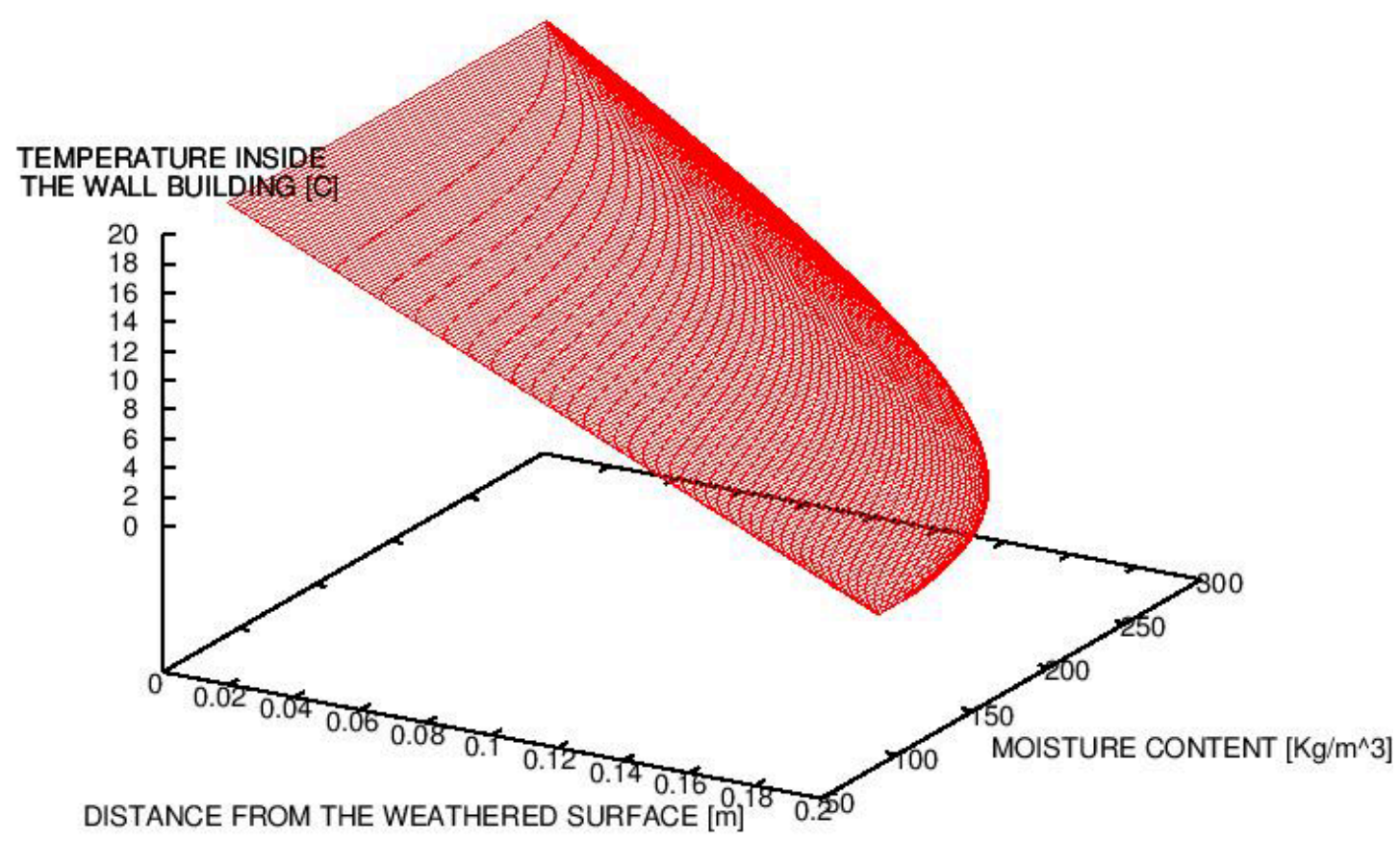

Figure 11. Spatial profile of the temperature of the wall of the building as a function of moisture content. Here, the wall is made of pumice concrete. The initial moisture content on the weathered surface is $\omega_{0}=300 \mathrm{Kg} / \mathrm{m}^{3}$. The external temperature is $0^{\circ} \mathrm{C}$. 
Calculations carried out in this contribution clearly prove that the presence of humidity causes additional expenditure of energy during the heating process of buildings. Many calculations are performed to show the impact of moisture in the heating process. To remedy this situation, two options are available to those who want to build a house:

(i) Build with normal concrete and cover the entire exterior walls with moisture-resistant materials. As an example, we can highlight solid plastic which is known to be perfect for wet conditions. The biggest concern is the relatively high price of solid plastic and the technique involved in assembling the two layers of the wall.

(ii)

In the second option, the internal partitions are made of normal concrete with all the external walls being made of pumice concrete. We can, of course, evoke the relatively high price of pumice concrete. However, this cost is amortized during heating process. In addition, we record a significant environmental benefit. Indeed, by consuming less energy, the environment is less attacked.

From our point of view, this second option should be the most appropriate. Calculations are made to encourage or dissuade people from following this direction. This approach will benefit them in the long term.

Comparisons are made to show the difference between the two modes of building. Comprehensive estimates are made. Calculations are made which make it possible to compare the energy expenditure allocated to the two construction methods involving the normal concrete and the pumice concrete.

Our approach leads to the conclusion that pumice concrete has the ability to better resist humidity.

The heating of buildings during winter has become a crucial environmental problem. This has become a global concern. The world community must take its responsibilities to face with strong determination this energetic crisis.

\section{Conclusions}

The fundamental principle of this study is to determine the amount of energy required to maintain the indoor temperature at $20^{\circ} \mathrm{C}$ whatever the weather and whatever the type of conditions faced by the occupants. These conditions include: moisture content of the wall [23], the outdoor temperature and the type of concrete.

The major area of energy consumption in buildings is heating. So, all initiatives aimed at addressing the energy used for heating in buildings should be encouraged. People need a minimum of comfort during the winter period. Without this minimum they can loss their live. So, this problem of heating becomes a humanitarian and a social preoccupation. The biggest energy challenge facing humanity is connected to heating of the buildings during winter period.

The aim of the work reported in this paper was to determine the influence of moisture content, outdoor temperature and the type of the concrete used for building, on the heating energy. Numerical calculations have been performed making use of the DOPRI5 fourth-and-fifth-order Runge-Kutta variable step integrator. We have deduced that the power provided for heating grows with the moisture content. So, the presence of moisture leads to additional energy costs.

We have established that small outdoor temperatures are associated with higher powers provided for heating. We have demonstrated that temperature inside the wall building increases with the moisture content. The type of concrete used is also decisive in this approach. We save about 50 percent of energy by using pumice concrete instead of normal concrete. The use of concretes of higher quality ensures thermal comfort and energy efficiency.

It is a fact that the worldwide energy consumption is based mostly on oil. The perpetual requirement of an energy efficiency policy could not be explained only by the impact created by the oil crisis but mainly by environmental concerns. Indeed, the more energy is solicited for the accomplishment of a given task, the more the environment is destroyed. It is worth nothing that the massive use of traditional energy sources naturally leads to the increase of greenhouse gas emissions such as carbon dioxide. Subsequently, the humanity is exposed to global warming. Hence, the energy crisis is closely linked to the environmental crisis. The capacity of each individual to minimize the amount of energy used in every circumstance should be our universal goal. This paper has proposed a methodology devoted to finding more accurate conditions that could enable us to minimize the amount of energy provided for heating of buildings. Indeed, no life can be imagined in a building during the winter period without energy. The involvement of international and national policies is essential to promote more efficient use of energy. In this sense, buildings construction should necessitate an urgent need of superior architecture and engineering designs. We must focus our attention on solutions of long term to ease the task of the population. Their respective governments and international organizations should naturally offer them possibilities to live in houses that meet higher quality standards. This option shall contribute to significantly lowering the amount of energy spent for heating.

Finally, a major place, in what concerns a sure and clean future, is represented by the efficient usage of energy. It is normal that new pathways should be continuously required to master the challenge of promoting energy efficiency. We believe that our contribution will impact future studies on the process of heating of buildings. Could this work bring some 
contribution to the global challenge concerning the protection of our environment?

\section{Nomenclature}

\section{Latin letters}

A water absorption coefficient $\left[\mathrm{kg} /\left(\mathrm{m}^{2} s^{1 / 2}\right)\right]$ [\%]

b moisture-related thermal conductivity supplement

$D_{\omega} \quad$ capillary transport coefficient for the suction process $\left[\mathrm{m}^{2} / \mathrm{s}\right]$

$\mathrm{L}$ thickness of a building wall $[\mathrm{m}]$

$\mathrm{S}$ section of a building wall $\left[\mathrm{m}^{2}\right]$

$\mathrm{t}$ time [s]

$\mathrm{T}$ absolute temperature $\left[{ }^{\circ} \mathrm{K}\right]$

$T_{i} \quad$ indoor temperature $\left[{ }^{\circ} \mathrm{K}\right]$

$T_{6} \quad$ outdoor temperature $\left[{ }^{\circ} \mathrm{K}\right]$

$T_{\chi} \quad$ temperature at a given position, $\mathrm{x}\left[{ }^{\circ} \mathrm{K}\right]$

$\mathrm{x}$ distance from a weathered surface $[\mathrm{m}]$

\section{Greek letters}

$\kappa$ coefficient of the moisture capillary conductivity $\left[\mathrm{Kg} /\left(m^{2} s^{1 / 2}\right)\right]$

$\Phi$ power supplied for the warming [W]

$\varphi$ power supplied for the warming per unit area $W / m^{2}$

$\lambda_{\omega}$ thermal conductivity of a moist building material $[W / m . K]$

$\lambda_{0} \quad$ thermal conductivity of a dry building material $[W / m . K]$

$\rho_{S} \quad$ bulk density of dry building material $\left[\mathrm{Kg} / \mathrm{m}^{3}\right]$

$\omega \quad$ moisture content $\left[\mathrm{Kg} / \mathrm{m}^{3}\right]$

$\omega_{f} \quad$ free water saturation $\left[\mathrm{Kg} / \mathrm{m}^{3}\right]$

\section{REFERENCES}

[1] International Energy Agency: World Energy Outlook, 2014

[2] Communication on the State of the Energy Union, 2016

[3] Pel L., Brocken H., Kopinga K., "Determination of moisture diffusivity in porous mediausing moisture concentration profiles," International Journal of Heat and Mass Transfer, vol. 39, no. 6, pp. 1273-1280, 1996. DOI:10.1016/0017-9310(95)00201-4

[4] Pel L., Kopinga K., Brocken H., "Determination of moisture profiles in porous building materials," Int. Symp. on Non-Destructive Testing in Civil Engineering (NDT-CE), Berlin, Germany, 1995, pp. 189-196
[5] Pel L., Kopinga K., Brocken, H., "Determination of moisture profiles in porous materials," Magnetic Resonance Imaging, vol. 14, no. 7, pp. 931-932, 1996. DOI: $10.1016 / \mathrm{s} 0730-725 \times(96) 00185-3$

[6] Pel L., Kopinga K., Brocken H., "Moisture transport in porous building materials," HERON, vol. 41, no. 2, pp. 95-105, 1996. https://research.tue.nl/en/publications/moist ure-transport-in-porous-building-materials

[7] National Concrete Masonry Association, "Preventing Water Penetration in Below-GradeConcrete Masonry Walls," 2001, TEK 19-3A.

https://ncma.org/resource/preventing-water-penetration-inbelow-grade-walls/

[8] Taoukil D., - Abdelmajid E. 1., Bouardi - Friedrich S., Abdelaziz M., - Hassan E., - Taib A., "Moisture content influence on the thermal conductivity and diffusivityof wood-concrete composite," Construction and building materials, vol. 48, pp. 104-115, 2013. https://www.sciencedirect.com/science/article/abs/pii/S095 0061813005850?via\%3Dihub

[9] Carmeliet J., Janssen H., Derluyn H., "An improved moisture diffusivity model for porous building materials," Proceedings of the 12th Symposium for Building Physics, Dresden, Germany, March, 2007. https://orbit.dtu.dk/en/pu blications/an-improved-moisture-diffusivity-model-for-por ous-building-materi

[10] Simo E., Dzali Mbeumo P. D., Mbami Njeuten J. C., " Moisture transfer in concrete: numerical determination of the capillary conductivity coefficient," Slovak Journal of Civil Engineering, vol. 25, no. 1, pp. 10-18, 2017. DOI:10.1515/sjce-2017-0002

[11] Kunzel H., "Does the volume-related or the mass-related moisture content determine the thermal conductivity of building materials?, " Bauphysik, vol. 8, no. H.2, pp. 33-39, 1986. https://hal.archives-ouvertes.fr/hal-00801345

[12] Cammerer J., Achtziger J., "Effect of the moisture content on the thermal conductivity of building materials and insulation products," Kurzberichte aus der Bauforschung, Bericht no. 115: pp. 491-494, 1985. https://doi.org/10.1007/978-3-540-32218-4_24

[13] Crank J., Nicolson P., "A Practical Method for Numerical Evaluation of Solutions of Partial Differential Equations of Heat Conduction Type," Proceedings of the Cambridge Philosophical Society, vol. 43, pp. 50-67, 1947. doi:10.1007- BF02127704.

[14] Charney J. G., Fjortoft R., Von Neumann J., "Numerical Integration of the Barotropic Vorticity Equation," Tellus, vol. 2, no. 4, pp. 237-254, 1950 doi:10.1111/j.2153-3490.1950.tb00336.x.

[15] Hairer E., Norsett S. P., Wanner G., " Solving Ordinary 1235 Differential Equations I," Springer-Verlag, Berlin, 1987. https://www.springer.com/gp/book/9783540566700

[16] Journal of Computational and Applied Mathematics, Dormand-Prince Method, vol. 15, no. 2, pp. 203-211, 1986 https://dl.acm.org/toc/jcam/1986/15/2

[17] Atkinson K. A., "An Introduction to Numerical Analysis (2nd ed.)," John Wiley and Sons, ISBN 0-471-50023-2.), Chapter 3, 1998 
[18] Schatzman M., "Numerical Analysis: A Mathematical Introduction," Clarendon Press, Chapter 4, Oxford. ISBN 0-19-850279-6, 2002

[19] Simo E., Kenhago Watia J. S., Songong Tsakeu S. C., Kenfack Donfack L. B., Makodjou Wafo M. E., Talla P. K., "Soils and sub-soils contamination: migration of petroleum to the ground surface accounting for variable permeability coefficient in compressible rocks," Global Scientific Journal, vol. 8, no. 4, pp. 1673-1692, 2002. https://www.globalscientificjournal.com/researchpaper/soil $\mathrm{s}$ and sub soils contamination migration of petroleum to the ground_surface accounting for_variable permeabi lity_coefficient_in_compressible_rocks_.pdf

[20] Simo E., kenhago Watia J. S., Songong Tsakeu S. C., Talla P. K., "Soils' Pollutions by Petroleums Accounting for Biodegradation and Concentration- Dependent Diffusivity. International," International Journal of Advanced Engineering Research and Science, vol. 6, no. 2, pp. 214-228, 2019. DOI:10.22161/ijaers.6.2.28
[21] Simo E., Kenhago Watia J. S., Songong Tsakeu S. C., Zambe J. I. C., Simo Kamdem, G. R., Tabekoueng F. W., "Migration of petroleum hydrocarbons from ground surface to groundwater accounting for a liquid Arrhenius model," International Research Journal of Public and Environmental Health, vol. 6, no. 7, pp. 144-154, 2019 https://journalissues.org/irjpeh/abstract/migration-of-petrol eum-hydrocarbons-from-ground-surface-to-groundwater-a ccounting-for-a-liquid-arrhenius-model-2/

[22] Isaacson E., "Herbert Bishop Keller Analysis of Numerical Methods Courier Corporation, Mathematics," 1994, pp. $1-541$.

[23] Mendes N., - Fernandes C. P., - Philippi P. C., - Lamberts R., " Moisture content influence on thermal conductivity of porous building materials," Seventh International IBPSA Conference. Moisture content influence on the thermal conductivity and diffusivity of wood-concrete composite. Construction and Building Material, Rio de Janeiro, Brazil, August 13-15, 2001, vol. 48, pp.104-115. 